ISSN 2658-4824 (Print)

УДК 782.9

DOI: 10.33779/2658-4824.2019.2.078-084

\section{О.И. КУЛАПИНА}

Саратовская государственная консерватория им. Л.В. Собинова

2. Саратов, Россия

ORCID: 0000-0002-4001-1877

kulapin@rambler.ru

\section{OLGA I. KULAPINA}

Saratov State Conservatoire named after L.V. Sobinov

Saratov, Russia

ORCID: 0000-0002-4001-1877

kulapin@rambler.ru

\section{На пути к открытию национального театра Калмыкии}

\footnotetext{
Развитие информационных технологий позволяет заметно расширить пространство неизведанного, обнаружив новые, порой необычные, удивительные и неожиданные факты: к примеру, из прошлого нашей страны, из истории становления её национальных культур. К одной из таких находок можно отнести тему, вызвавшую неподдельное внимание автора. Она посвящена начальному этапу работы по открытию национального театра Калмыкии. Ознакомление читателя с этим интересным событием и составляет иель настоящей статьи. Содержание её строится на данных по подготовке и осуществлению первой грандиозной театрализованной постановки - спектакля «Улан-Сар» самобытного массового зрелища, объединившего разные виды искусства (театр, музыку, хореографию) с этнографией и фольклором Калмыкии. Поскольку спектакль имел межрегиональный статус, в статье называются города и организации, массово участвующие в этом масштабном действе, а также его устроители. Особое место занимает критико-аналитическая статья профессора, доктора филологических наук, фольклориста А.М. СмирноваКутаческого (1876-1958), посвящённая детальному изучению данной постановки. Говорится и о трагической судьбе её автора Санджи Каляева (1905-1985), энтузиаста, организатора, первого директора национального театра Калмыкии, в будущем народного поэта республики.
}

\section{On the Path Toward the Establishment of the National Theater of Kalmykia}

The development of informational technologies makes it possible to expand to a considerable degree the domain of the unexplored, revealing new, at times unusual, remarkable and unexpected facts, for example, from the past history of our country, from the history of the formation of its national cultures. One such discovery may be deemed to be the information about the initial stage of work on the establishment of the national theater of Kalmykia. The reader's familiarization with this interesting event is what comprises the goal of the present article. Its content includes information about the preparation and the realization of the grandiose theatrical premiere of the performance of "Ulan-Sar" an original mass entertainment event which united theater, music and choreography with ethnography and folklore.

Since the performance possessed an interregional status, the article lists the cities and organization which massively participated in this large-scale event, as well as its organizers. A special place is taken by information about the critical-analytical article of professor, Doctor of Philological Sciences, folklorist Alexei Smirnov-Kutachesky (1876-1958) devoted to detailed study of this production. Mention is also made of the tragic fate of its author, Sandzhi Kalyayev (1905-1985), a great enthusiast, the organizer and first director of the national theater of Kalmykia, subsequently the first people's poet of the republic. 


\section{Ключевые слова:}

национальная культура, Калмыкия, калмыцкий театр, массовая постановка «Улан-Сар», джангар, Санджи Каляев, Алексей Смирнов-Кутаческий.
Keywords:

national culture, Kalmykia, Kalmyk theater, mass production of "Ulan-Sar", dzhangar, Sandzhi Kalyayev, Alexei Smirnov-Kutachesky.

Для цитирования/For citation:

Кулапина О.И. На пути к открытию национального театра Калмыкии // ИКОНИ / ICONI. 2019. № 2. C. 78-84. DOI: 10.33779/2658-4824.2019.2.078-084.

$\mathrm{B}$ развитии национальной культуры Калмыкии историческую важность приобрёл первый массовый музыкально-эпический спектакль на калмыцком языке «Улан-Сар» («Красный месяц», 1931), содержавший революционную пропаганду и агитировавший за новую жизнь калмыцкого народа. В синтезированном представлении, по грандиозности замысла и ассоциации сравнимом с немецкой мифологией - вагнеровской оперой «Гибель богов» из тетралогии «Кольцо нибелунга» [9], была задействована сборная труппа самодеятельных артистов, состоящая почти из 325 человек ${ }^{1}$. В её состав входили студенты коммунистического вуза, государственного университета имени Н.Г. Чернышевского, учащиеся медицинского техникума, педагогического и кооперативного институтов Саратова, педагогического рабочего факультета Калмыкии, Астраханской калмыцкой драматической школы-студии, открытой в 1927 году², а также участники художественной самодеятельности, пионеры и школьники. Ведомая патриотической идеей молодёжь горячо взялась за подготовку постановки; неустанно велись репетиции, а анализ самого исполнения охватывал диапазон от хвалебных речей до жарких споров.

Грандиозное действо под руководством ректора коммунистического вуза Саратова и заведующего Культпромом крайкома ВКП(б) Г. Бройдо осуществляла группа авторов, в состав которой были включены представители Саратовского педагогического института во главе со студентом Санджи Каляевым, совмещавшим функции литератора (автора пьесы), драматурга и сценариста. В штаб по постановке спектакля входили также ленинградский художник М. Плачек, московский хореограф Е. Марголис ${ }^{3}$. За музыкальное оформление вместе с другими авторами музыки отвечал выпускник Московской государственной консерватории имени П.И. Чайковского композитор А. Абрамский. В качестве режиссёров выступали представители Саратовского театра драмы, а также деятели культуры, прибывшие из Калмыкии.

Спектакль, созданный по инициативе национального калмыцкого факультета Саратовского госуниверситета ${ }^{4}$ и изобилующий фольклорными номерами, стал первым композиционным и оркестровым опытом освоения народной музыки. Динамичное развитие драматургической фабулы спектакля, имевшего богатую этнографическую основу, передавалось через показ эпической картины о калмыцком быте с привлечением национального эпоса джангара. Зрители, наблюдавшие за театрализованной постановкой, со всей очевидностью могли заметить в ней синкретизм разных видов искусства. Действие сопровождалось игрой симфонического оркестра и хурульного оркестра, состоящего из редких духовых и ударных инструментов - бишкуры, бюря, нередко сопровождавших храмовое буддистское 
богослужение ${ }^{5}$. Здесь же использовалась игровая пантомима и танец масок. Представлениям на открытом воздухе сопутствовали традиционная калмыцкая борьба и скачки на лошадях. Грандиозное действо было богато иллюстрировано вставными музыкальными номерами. По ходу спектакля, наряду с современными колхозными частушками, звучали напевы старинных калмыцких песен и игра на популярных национальных инструментах - домбре, дудках, трубах, гармониках.

О масштабах постановки поочерёдно могли судить жители нескольких городов. Сначала пьеса была сыграна недалеко от Астрахани, на берегу Тинакского озера, затем на сцене Саратовского драматического театра имени Карла Маркса ${ }^{6}$ и в Камышине. В 1932 году спектакль повторили в Москве, в здании кинотеатра «Колизей» на Чистых прудах. При этом московский спектакль давался специально для членов советского правительства, в целом одобривших постановку, что незамедлительно сказалось на формировании театрального искусства Калмыкии. В 1935 году после доработки пьеса «УланСар» с огромным успехом прошла, наконец, и в самой Калмыкии, что свершилось на Первой областной олимпиаде самодеятельного искусства в Элисте, ставшей осенью того же года столицей республики. Именно там, на своей малой родине, будущие профессиональные артисты ощутили вкус заслуженных аплодисментов.

Профессор А.М. Смирнов-Кутаческий ${ }^{7}$ посвятил постановке специальный опус «„Улан-Сар“ как поэтическое произведение», где содержался анализ спектакля [1; 9]. В статье, опубликованной в газете «Ленинский путь» (1935, № 73), автор пишет, что вся агитационная пьеса, передающая картину «победного шествия возрождённой страны, <..> составлена из разнообразных отрывков фольклора: тут и старинные песни, „песни без слов“, и героический „Джангар“..., и пантомимы домашних работ, и гимн коню, и лёгкие сатирические выступления, - всё это со звуками домбрачей, дудочников, гармонистов, трубачей, вплоть до губной гармошки, и пляски, пляски без конца» [9].

В той же работе учёный пытается выяснить жанровую основу представления, отмечая следующие его особенные моменты.

1. Отвергая драму из-за отсутствия героя и недостаточного развития сюжетной фабулы, он подчёркивает наличие эпического начала пьесы и рассредоточенных бытовых номеров, не связанных между собой драматургически (например, раскрытие истории бедняка во второй картине).

2. Не видит он и трагедии, хотя предполагает возможности сосредоточения этнического действия в большой трагедийной картине, апеллируя к вагнеровской трилогии. Вместе с тем находит сходство с первой революционной постановкой молодой страны Советов - «Мистериейбуфф» В.В. Маяковского (1918).

3. Автор задаётся вопросом: «может быть, это так называемая народная драма со сценическими вставками из фольклора?» [там же]. И тут же опровергает наличие такой жанровой основы, поскольку «здесь фольклорный материал не вставки, не художественные иллюстрации, а подлинное коренное содержание произведения» [там же].

В результате критического анализа жанровой основы спектакля СмирновКутаческий выявляет существенные недостатки в его сценическом воплощении. Согласно его точке зрения, они заключаются, во-первых, в реализации живого, непосредственного участия в действии зрителей (при исполнении хоровых песен, например революционных, проведении национальных игр и пр.); во-вторых, в возможном насыщении сюжетной фабулы подлинно драматическим началом, например, о тяготах жизни крестьянина-бедняка. К числу мелких замечаний относятся: а) малое количество комических номеров, б) непропорциональность 
в соотношении постановочных компонентов, либо излишне пролонгированных, либо слишком сжатых.

В итоге автор статьи приходит к неоднозначному выводу. С одной стороны, подчёркивает новизну и необычность описываемого грандиозного действа, идущего в ногу со временем и наполненного многими интересными находками, особенно этнического плана, с другой признаёт его слабость и несовершенства. Он пишет о том, что «опыт нового творчества находится здесь в зачаточном состоянии и содержит много интересных начинаний. Это - «фольклористическая феерия из ярких оригинальных блёстков местного фольклора. В пёстрой движущейся оживлённой картине даны все самые характерные элементы поэтики. В виде истоков звучат торжественные архаичные аккорды в устах убелённого старика; сатирические сценки рисуют местный быт, широким раздольем льётся бесконечная тягучая песня и над всем организующая и быт, и мировоззрение советская современность в митингах, лозунгах, декламациях, маршировках, овациях и проч. Красочная феерия дана в яркой национальной форме и вся живёт боевым социалистическим содержанием наших дней» [там же].

Постановка массового музыкального представления, больше напоминавшего масштабное эпическое действо, была первым шагом на пути учреждения театрального образования и создания национального театра Калмыкии. Санджи Каляевич Каляев (1905-1985) автор, ставший активным устроителем и участником сценического воплощения «Улан-Сара» и получивший известность как первый народный поэт Калмыкии (с 1965 года), в своих письмах пишет: «Нижне-Волжский краевой комитет КПСС, принимая во внимание удовлетворительные результаты первой серьёзной постановки, решил организовать Калмыцкий техникум искусств, который вначале базировался в Саратове, а потом был переведён в Астрахань» ${ }^{8}$ [2]. Техникум, учреждённый в 1934 году, имел два отделения: театральное (актёрское) и музыкальное, куда входили классы фортепиано, баяна и скрипки. Несмотря на сложности с набором учащихся, первый выпуск молодых специалистов состоялся уже в 1936 году. Весной того же года обком партии принял решение об открытии Калмыцкого государственного национального театра-студии, которое было приурочено к 19-й годовщине Великой Октябрьской социалистической революции и состоялось в предпраздничные дни.

Каляев был назначен директором театра, ставшего его любимым детищем. Главным режиссёром стал Владимир Гольдфельд (Гольд). Театр открылся премьерой пьесы Хасыра Сян-Белгина «Борец-сирота» [5], горячо принятой публикой. Несмотря на довольно острую репертуарную политику, уже в свой первый сезон 1936-1937 годов труппа театра осуществила постановку восьми спектаклей на калмыцком языке 9 . Среди них: классическая пьеса А.Н. Островского «Гроза» (перевод на калмыцкий язык Хонина Косиева), «Цыгане» А.С. Пушкина, пьеса Б. Манджиева «В борьбе закаляемся», пьесы советских драматургов В. Гусева и А. Корнейчука. Готовились и другие премьеры. Профессионально владевший языкознанием С. Каляев перевёл с русского языка на калмыцкий несколько популярных произведений: «Овечий источник» Лопе де Вега, «Лекарь поневоле» Ж.Б. Мольера, «Мятеж» Д. Фурманова ${ }^{10}$. В том же году была открыта Калмыцкая студия при Государственном институте театрального искусства имени Луначарского, возглавляемая А.Н. Фурмановой, супругой известного писателя.

Однако дальнейшая судьба директора театра сложилась довольно трагично. Уже весной 1937 года по ложному доносу он был объявлен чуждым элементом и по троцкистскому делу снят с руководящей должности. Будучи врагом народа (к тому же «буржуазным националис- 
том» и «сыном дворянина»), исключён из Союза писателей, осенью того же года арестован и приговорён к восьми годам трудовых лагерей, в том числе на приисках Сибири. В 1939 году из-за тяжёлой болезни его отправили в лагерь для инвалидов в Магадан, через два года - в лагерь недалеко от Тайшета. Зимой 1943 года по состоянию здоровья Каляева освободили, разрешив жить в Казахстане, но ему, как переселенцу, запрещалось работать по специальности. На протяжении долгих семи лет он довольствовался малооплачиваемой работой конюха. С 1950 по 1957 год он преподавал в казахской шко- ле-семилетке русский язык и литературу, в 1956 году частично реабилитирован, а осенью 1958-го, после полной реабилитации и восстановления в правах, вернулся в Калмыкию [5, с. 243].

Несмотря на превратности судьбы, Каляев достиг очень многого в деле становления национальной культуры республики. Благодаря энтузиазму, кипучей деятельности им и его сподвижниками был не только заложен фундамент для открытия национального театра Калмыкии, но и подготовлено начало для театрального образования в республике ${ }^{11}$.

\section{थ ПРИМЕчАНИЯ $\sim$}

1 По другим источникам - 300-320 человек [2; 4].

2 Считается, что на её основе и был организован «передвижной калмыцкий театр» [3].

3 Е.М. Марголис - будущая жена

С.К. Каляева.

4 В качестве справки отметим, что калмыцкое отделение, существовавшее в рамках филологического факультета классического университета Саратова, было открыто в 1929 году. Вскоре аналогичный филиал появился в пединститутах Саратова и Астрахани. Учреждение таковых было необходимо для обеспечения слабой образовательной системы Калмыкии. Причём в Астрахани функционировал факультет калмыцкого языка и литературы, просуществовавший до 1932 года, вплоть до открытия Калмыцкого педагогического института республиканского значения. Калмыцкое отделение Саратовского пединститута к этому времени уже осуществило первый выпуск студенческой группы из семи человек, в числе которых был и С.К. Каляев. По другим данным, «в январе 1932 года в Саратове был организован техникум национального калмыцкого искусства, который готовил калмыцких артистов» [3].

5 Такой строгий вид музицирования, согласно религиозным канонам, был под запретом и не допускал публичного исполнения. В этом же контексте интересно отметить признанный факт совмещения в калмыцкой вере двух религиозных традиций: буддийской и шаманской [10]. 6 В 2003 году театр был переименован, ныне он носит имя известного русского актёра И.А. Слонова.

7 А.М. Смирнов-Кутаческий (в некоторых изданиях А.M. Смирнов-Кутачевский, 1876-1958) - известный советский филолог, фольклорист и этнограф, неоднократно бывавший в Калмыкии, живо интересовался этническими сокровищами республики, что отражено в таких его работах, как «Об одной особенности фольклора Калмыкии», «Организовать научно-исследовательскую работу по фольклору Калмыкии», «О собирании фольклора" [5].

8 С. Каляев был директором техникума, дислоцированного в Астрахани.

9 Переводу текстов классических спектаклей способствовал Союз писателей Калмыкии, начавший такую работу ещё за полгода до открытия театра.

10 О дальнейшей судьбе театра см. на сайте Калмыцкого государственного драматического театра имени Баатра Басангова.

11 В качестве дополняющего и поясняющего материала к нашей статье может служить работа И.В. Батиновой о предвестниках калмыцкого театра: мистериях Цам, самодеятельных театральных кружках и драмстудиях. (См.: Батинова И.В. Истоки зарождения театра в Калмыкии / Вестник Калмыцкого института гуманитарных исследований РАН. 2012. № 4. С. 29-33.) 


\section{$\stackrel{\mu}{\sim}$ литеРАТУРА $\sim$}

1. Басангова Т.Г. О вкладе профессора Смирнова-Кутаческого в калмыцкую

фольклористику. URL: www.academia.edu/6385836 (Дата обращения: 27.02.2018).

2. Каляев С.К. Письма Еве: Письма и другие документальные материалы к биографии

С.К. Каляева / Сост. Э.С. Каляева. Элиста: Калмыцкое кн. изд-во, 2001. 288 с.

3. Каляев С.К. Рождение театра. URL: www.famhist.ru/famhist/kaliaev/0003468f.htm (Дата обращения: 21.02.2018).

4. Камова Р.М. О национально-культурной специфике в сфере этнического взаимодействия // Этносоциум и межнациональная культура. 2017. № 6 (108). С. 89-92.

5. Кулапина О.И. Как создавался национальный театр Калмыкии // Музыкальное искусство и наука в современном мире: теория, история, исполнительство, педагогика: Сб. ст. по материалам VI Международной научной конференции. Астрахань: ООО ПКФ «Триада», 2018. С. 240-243.

6. Михайлова Н.В., Иглин Д.А., Гришин О.Е. Взаимосвязь массовой культуры и индустрии видеоигр: политико-философский аспект // Этносоциум и межнациональная культура. 2018. № 8 (122). С. 32-40.

7. Олчанова Ц.В. Калмыцкая национальная интеллигенция: формирование и развитие в конце XIX века — первой половине XX века. Элиста: Изд-во Калмыцкого ун-та, 2016. 174 с.

8. Сафарова Л.Г. О музыке и музыкантах Калмыкии. Элиста: Джангар, 2009. 237 с.

9. Смирнов-Кутаческий А.М. «Улан-Сар» как поэтическое произведение / А.М. СмирновКутаческий в Калмыкии. URL: studfiles.net/preview/3995110 (Дата обращения: 24.02.2018)

10. Уланов М.С. Религиозная культура калмыцкого этноса в контексте взаимодействия буддийской и шаманской традиций // Вестник Калмыцкого ун-та. 2016. № 1 (29). С. 112-119.

\section{Об авторе:}

Кулапина Ольга Ивановна, доктор искусствоведения, кандидат философских наук, профессор кафедры теории музыки и композиции, Саратовская государственная консерватория им. Л.В. Собинова (410012, г. Саратов, Россия), ORCID: 0000-0002-4001-1877, kulapin@rambler.ru

\section{e REFERENCES $\sim$}

1. Basangova T.G. O vklade professora Smirnova-Kutacheskogo $v$ kalmytskuyu fol'kloristiku [About the Contribution of Professor Smirnov-Kutachesky to the Kalmyk Folk Music Studies]. Available at: www.academia.edu/6385836 (Accessed: 27.02.2018).

2. Kalyaev S.K. Pis'ma Eve: Pis'ma i drugie dokumental'nye materialy k biografii S.K. Kalyaeva [Letters to Eve: Letters and Other Documentary Materials of the Biography of S.K. Kalyaev]. Comp. by E.S. Kalyayeva. Elista: Kalmyk Book Publishing House, 2001. 288 p.

3. Kalyaev S.K. Rozhdenie teatra [The Birth of the Theater]. Available at: www.famhist.ru/famhist/kaliaev/0003468f.htm (Accessed: 21.02.2018).

4. Kamova R.M. O natsional'no-kul'turnoy spetsifike v sfere etnicheskogo vzaimodeystviya [About National-Cultural Specificity in the Sphere of Ethnic Interaction]. Etnosotsium i mezhnatsional'naya kul'tura [Ethnic Society and International Culture]. 2017. No. 6 (108), pp. 89-92.

5. Kulapina O.I. Kak sozdavalsya natsional'nyy teatr Kalmykii [How the National Theater of Kalmykia was Created]. Muzykal'noye iskusstvo i nauka v sovremennom mire: teoriya, istoriya, ispolnitel'stvo, pedagogika [Musical Art and Scholarship in the Modern World: Theory, History, Performance, Pedagogy]. Sb. st. po materialam VI Mezhdunarodnoy nauchnoy konferentsii [Compilation of Articles of the 6th International Scholarly Conference]. Astrakhan: OOO PKF “Triada” [Limited Liability Company Industrial-Commercial Firm “Triada”], 2018, pp. 240-243.

6. Mikhaylova N.V., Iglin D.A., Grishin O.E. Vzaimosvyaz' massovoy kul'tury i industrii videoigr: politiko-filosofskiy aspekt [The Relationship of Popular Culture and the Industry of Video 
Games: the Political and Philosophical Aspect]. Etnosotsium i mezhnatsional'naya kul'tura [Ethnic Society and International Culture]. 2018. No. 8 (122), pp. 32-40.

7. Olchanova Ts.V. Kalmytskaya natsional'naya intelligentsiya: formirovanie i razvitie $v$ kontse XIX veka - pervoy polovine XX veka [The Kalmyk National Intelligentsia: Its Formation and Development in the Late 19th Century and the First Half of the 20th Century]. Elista: Kalmyk University Press, 2016. $174 \mathrm{p}$.

8. Safarova L.G. O muzyke i muzykantakh Kalmykii [About the Music and Musicians of Kalmykia]. Elista: Dzhangar, 2009. 237 p.

9. Smirnov-Kutacheskiy A.M. «Ulan-Sar» kak poeticheskoe proizvedenie [“Ulan-Sar” as a Poetic Work]. A.M. Smirnov-Kutacheskiy v Kalmykii [A.M. Smirnov-Kutacheskiy in Kalmykia]. Available at: studfiles.net/preview/3995110 (Access date: 24.02.2018).

10. Ulanov M.S. Religioznaya kul'tura kalmytskogo etnosa v kontekste vzaimodeystviya buddiyskoy i shamanskoy traditsiy [Religious Culture of the Kalmyk Ethnos in the Context of the Interaction of Buddhist and Shamanic Traditions]. Vestnik Kalmytskogo universiteta [Bulletin of the Kalmyk University]. 2016. No. 1 (29), pp. 112-119.

About the author:

Olga I. Kulapina, Dr.Sci. (Arts), Ph.D. (Philosophy), Professor at the Department of Music Theory and Composition, Saratov State Conservatoire named after L.V. Sobinov (410012, Saratov, Russia), ORCID: 0000-0002-4001-1877, kulapin@rambler.ru

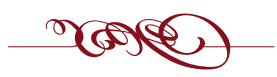

